This item was submitted to Loughborough's Research Repository by the author.

Items in Figshare are protected by copyright, with all rights reserved, unless otherwise indicated.

\title{
Managing compliance with the World Anti-Doping Code: China's strategies and their implications
}

PLEASE CITE THE PUBLISHED VERSION

https://doi.org/10.1177/1012690218805402

PUBLISHER

SAGE Publications $@$ The Authors

VERSION

AM (Accepted Manuscript)

\section{PUBLISHER STATEMENT}

This work is made available according to the conditions of the Creative Commons Attribution-NonCommercialNoDerivatives 4.0 International (CC BY-NC-ND 4.0) licence. Full details of this licence are available at: https://creativecommons.org/licenses/by-nc-nd/4.0/

\section{LICENCE}

CC BY-NC-ND 4.0

\section{REPOSITORY RECORD}

Tan, Tien-Chin, Alan Bairner, and Yu-Wen Chen. 2018. "Managing Compliance with the World Anti-doping Code: China's Strategies and Their Implications". Loughborough University. https://hdl.handle.net/2134/35746. 

(

\section{Managing Compliance with the World Anti-Doping Code: China's Strategies and their Implications}

\author{
Abstract
}

With the problems of doping in sport becoming more serious, the World AntiDoping Code was drafted by the World Anti-Doping Agency (WADA) in 2003 and became effective one year later. Since its passage, the Code has been renewed four times, with the fourth and the latest version promulgated in January, 2015. The Code was intended to tackle the problems of doping in sports through cooperation with governments to ensure fair competition as well as the health of athletes. To understand China's strategies for managing compliance with the Code and also the implications behind those strategies, this study borrows ideas from theories of compliance. China's high levels of performance in sport, judged by medal success, have undoubtedly placed the country near the top of the global sports field. Therefore, how China acts in relation to international organizations, and especially how it responds to WADA, is highly significant for the future of elite sport and for the world anti-doping regime. In response to WADA, China developed strategies related to seven institutional factors: 'monitoring', 'verification', 'horizontal linkages', 'nesting', 'capacity building', 'national concern' and 'institutional profile'. As for the implications, the Chinese government is willing and able to comply with the WADA Code. In other words, the Chinese government is willing to pay a high price in terms of money, manpower and material resources so that it can recover from the disgrace suffered as a result of doping scandals in the 1990s. The government wants to ensure that China's prospects as a participant, bidder and host of mega-sporting event are not compromised, especially as the host of the 2022 Winter Olympics in Beijing.

Key Words: China, Compliance, Government, Strategy, World Anti-Doping Code 5 (1) 


\section{Introduction} goals, however well-intentioned, can motivate some athletes to use substances to enhance their performance when disappointing results might adversely affect their social status, monetary pay-offs or other forms of rewards (Houlihan, 2002a, 2002b). A winning-obsessed culture has led to numerous tragedies with athletes dying while competing due to the effects of doping. As far as the International Olympic Committee (IOC) is concerned, the death of a cyclist at the 1960 Rome Olympics and the tragic passing of a British cyclist during the 1967 Tour de France sounded alarm bells about the need to tackle doping. A series of doping scandals led to the formation of the IOC Medical Commission, which began conducting drug tests at the Olympics (Wilson \& Derse, 2000). However, as doping became rampant, the Commission found itself unable to tackle the problem on its own and calls for an anti-doping agency, independent of the IOC, were eventually answered in 1999 when the World Anti-Doping Agency (WADA) was established. However, as a non-governmental organization, WADA could only issue non-binding guidelines and had limited impact on nation states. To alter this situation, WADA began working with the United Nations Educational, Scientific and Cultural Organization (UNESCO) in the hope of exerting greater influence over national governments. With UNESCO's support, WADA held the Second World Conference on Doping in Sport in Copenhagen, Denmark, in 2003, when 73 countries signed the Copenhagen Declaration on Anti-Doping in Sport (Liu, 2003). The following year, WADA introduced the World Anti-Doping Code (hereinafter referred to as 'the Code') ${ }^{1}$ (Houlihan, 2008), hoping to combat doping with the support of national governments, to ensure fairness in sport and to protect the health of athletes. Of course, doping was not exclusive to the Olympics. Many professional sports also fell victim to the use of performance enhancing drugs. In recent years, several high-profile athletes have been caught doping, including Major League Baseball player Barry Bonds, the American sprinter Justin Gatlin and seven-time Tour de France winner Lance Armstrong. In early 2016, Russian tennis star Maria Sharapova tested positive for meldonium at the Australian Open. This relatively minor scandal was followed by revelations that Russia had engaged in large-scale systematic doping, causing uproar among sports fans around the world. These incidents raise tantalizing questions: Why has WADA failed to control doping effectively since its inception? Could this be the consequence of governments' unwillingness to comply with the Code? If so, what

\footnotetext{
1 Since its passage in 2003, the WADA Code has been renewed four times. The latest version 4.0 went into effect in January, 2015 (World Anti-Doping Agency [WADA], 2015b).
} 
strategies have states adopted in response to the Code and what are the implications behind these strategies? By addressing these questions, we can acquire a better understanding of how the Code can be effectively implemented and whether doping can be eradicated, reduced to an acceptable level, or controlled at the present level.

At present, most studies on sports doping focus on prohibited substances, prohibited methods or testing methods (Lombardi, Perego, Sansoni, \& Banfi, 2016; Wang, Zhou, Liu, Dong, \& Zhang, 2017), the use of prohibited substances and drug test adulterations (Antonopoulos \& Hall, 2014; Maughan, 2007), ethical issues relating to athlete support personnel (Miah, 2006; Newsham \& Mokha, 2017) and athlete privacy and human rights in doping control (Elbe \& Overbye, 2014; Waddington \& Møller, 2014). Other researchers have examined WADA's anti-doping policies and their effectiveness in doping control (Houlihan, 2004; Loland \& Hoppeler, 2011; Stewart \& Smith, 2004; Wagner, 2011) or the appropriateness of anti-doping policies (de Hon, 2017; Efverström, Bäckström, Ahmadi, \& Hoff, 2016; Malcolm \& Waddington, 2008; Houlihan, 2015; Hunt, 2015). Also examined have been impact of the prohibited lists and the whereabouts requirements on athlete privacy and welfare (Henne, 2015; Sefiha \& Reichman, 2016) and on athlete health and anti-doping education (Henning \& Dimeo, 2015; Mazanov, Huybers, \& Connor, 2012). As shown above, research on sports doping, thus, mainly takes a microscopic view centred on athletes or their support personnel. Although some studies touch on the institutional and policy aspects of anti-doping, few examine compliance at a national level or from a governmental perspective. Among these, studies by Houlihan (2014) and Hanstad \& Houlihan (2015) are the most relevant to the present study. Houlihan (2014) first looked at compliance from WADA and UNESCO perspectives, discussing how the two international bodies bring signatories into compliance. His main focus, however, was on the organization's top-down governance and not the signatories' response to WADA which is where this study places its emphasis. Furthermore, Houlihan (2014) only interviewed two officials from WADA and UNESCO and did not indicate any contact with officials from the signatory states. Understandably, the data collected through his interviews only comprise a small portion of his paper, the majority of which consists of a literature review. Nevertheless, Houlihan (2014) examined anti-doping policy by looking at compliance, which is an area of research worth pursuing. Hanstad and Houlihan (2015) later discussed how bilateral collaboration facilitates anti-doping, using the example of Norway, an antidoping role model, working with China, a repeated violator of international anti-doping rules. Although the paper sheds light on the interactive and cooperative relationship between China and Norway, its primary focus is limited to the anti-doping history of the two countries and their collaboration. Little is said about how the two countries 
actually respond to the WADA Code. Although these two papers (Houlihan, 2014; Hanstad \& Houlihan, 2015) were of value to us in terms of theoretical application and literature review, neither of them followed the same research direction as the present study.

Previous scholars have discussed China's compliance with the Code. For example, according to Yang and Leung (2008) and Fan and Lu (2012), following the doping scandals involving Chinese athletes at the 1994 Asian Games in Hiroshima and the 1998 FINA World Championships, China began to take anti-doping seriously, hoping to restore its reputation and respond to growing international pressure. By that time, the doping crisis not only threatened to jeopardize Beijing's chances of competing at Sydney 2000, it also appeared that China's bid for the Beijing Games could be derailed (Fan \& Lu, 2012, p. 140). Both studies went a step further by praising the Chinese government's willingness to comply with WADA and revamping its anti-doping system. However, the limitations of both studies are evident. First, although Fan and Lu (2012) explained the impact of doping on China using historical accounts and attempted to delineate the evolution of China's anti-doping policies, by adopting documentary analysis as their research method, they merely identified connections between related events without referring to the policy discourse of important stakeholders or to other policy documents. Yang and Leung (2008) pointed out that China achieved continued progress in relation to anti-doping. They based their argument on the fact that the Chinese swimming team passed all drug tests while winning multiple medals in international competitions in 2004. However, their study only cited official figures and media reports, their arguments being corroborated by field surveys. As a result, the findings did not offer a complete picture of China's anti-doping policy. In addition, neither of the two studies used theories to inform their analysis and constantly ran the risk of being overly speculative. Lacking any theoretical basis and having failed to use field surveys as supporting documents, the two studies were unable to fully capture China's anti-doping policy and the implications behind its compliance strategies. Therefore, the aim of the present study is to overcome the limitations of previous research by establishing a theoretical basis and by analyzing data collected from semistructured interviews. The authors of this study have sought to answer the following questions: (1) What were China's strategies for managing compliance with the Code after 2004? (2) What were the main drivers and the significance of China's compliance strategies? To answer these questions, this study is divided into two parts; the first examines China's strategies for managing compliance with the Code and the second investigates the implications of these strategies. 


\section{Theoretical Framework and Research Methods}

The analytical framework of the seven institutional factors for this study is based on Haas and Bilder's (2003) 'compliance theories' used here for the purpose of scrutinizing China's compliance strategies and their implications since signing up to the Code. The theoretical framework used specifically in the analysis of strategies and implications is as follows.

According to Haas and Bilder (2003), the international regime induces state actors to comply mainly through the following means: 'monitoring', 'verification', 'horizontal linkages', 'nesting', 'capacity building', 'national concern' and 'institutional profile'. In 'monitoring', the regime demands that states honor their responsibilities and obligations, and inspectors oversee their compliance. In 'verification', the regime approves and certifies state compliance or empowers states to enforce anti-doping policies. 'Horizontal linkages' are connections built between organizations to help bring states into compliance. Enhanced interaction between organizations creates the collective momentum needed to encourage states to comply. 'Nesting' entails tying international norms to high-level issues to raise awareness. 'Capacity building' refers to the provision or withholding of resources as a means to encourage or force states 'National concern' means raising awareness among social elites or the general public so that the issue receives greater attention. Finally, 'institutional profile' calls on regimes to strengthen their system or raise the level of discourse. In the context of this study, the WADA-led international regime seeks to bring states into compliance by implementing the Code.

To satisfy the research aims of the study, the researchers designed an analytical framework based on the seven institutional factors identified by Haas and Bilder (2003). The result is a similar list of seven factors characterizing the WADA-led regime's efforts in inducing states to comply. Based on the 2015 version of the WADA Code, we identified seven factors of compliance and with them developed our interview outline (see Table 1). By 'monitoring', the regime demands that states comply with the Code and push for necessary domestic legislation or amendments. By 'verifying', WADA accredits national anti-doping laboratories and certifies state compliance. By forging 'horizontal linkages', WADA encourages cooperation between different anti-doping agencies. Through 'nesting', WADA stresses the importance of anti-doping on national agendas. 'Capacity building' helps expand states' capacity to enforce anti-doping policies. By raising 'national concern', WADA calls for more public education about anti-doping control and an increase in the publicity for anti-doping issues through promotions. 'Institutional profile' calls for efforts to stimulate genuine interactions between states and international organizations, such as WADA, IOC and UNESCO. The purpose is to increase the level of attention paid by each state to anti-doping. As 
1 shown above, this study has listed the factors which explain how WADA seeks to induce 2 international and national sports bodies to comply. It has also described the 3 responsibilities and obligations that WADA demands from signatories. These

4 discussions helped determine the dimensions of our analysis and also helped us to 5 prepare, in a more systematic fashion, an interview outline to be used for questions 6 about 'strategies'. The researchers conducted in-depth interviews with Chinese officials 7 who have responsibility for devising China's anti-doping policies (see table 2).

Table 1 Interview outline (Seven factors of compliance with the WADA Code)

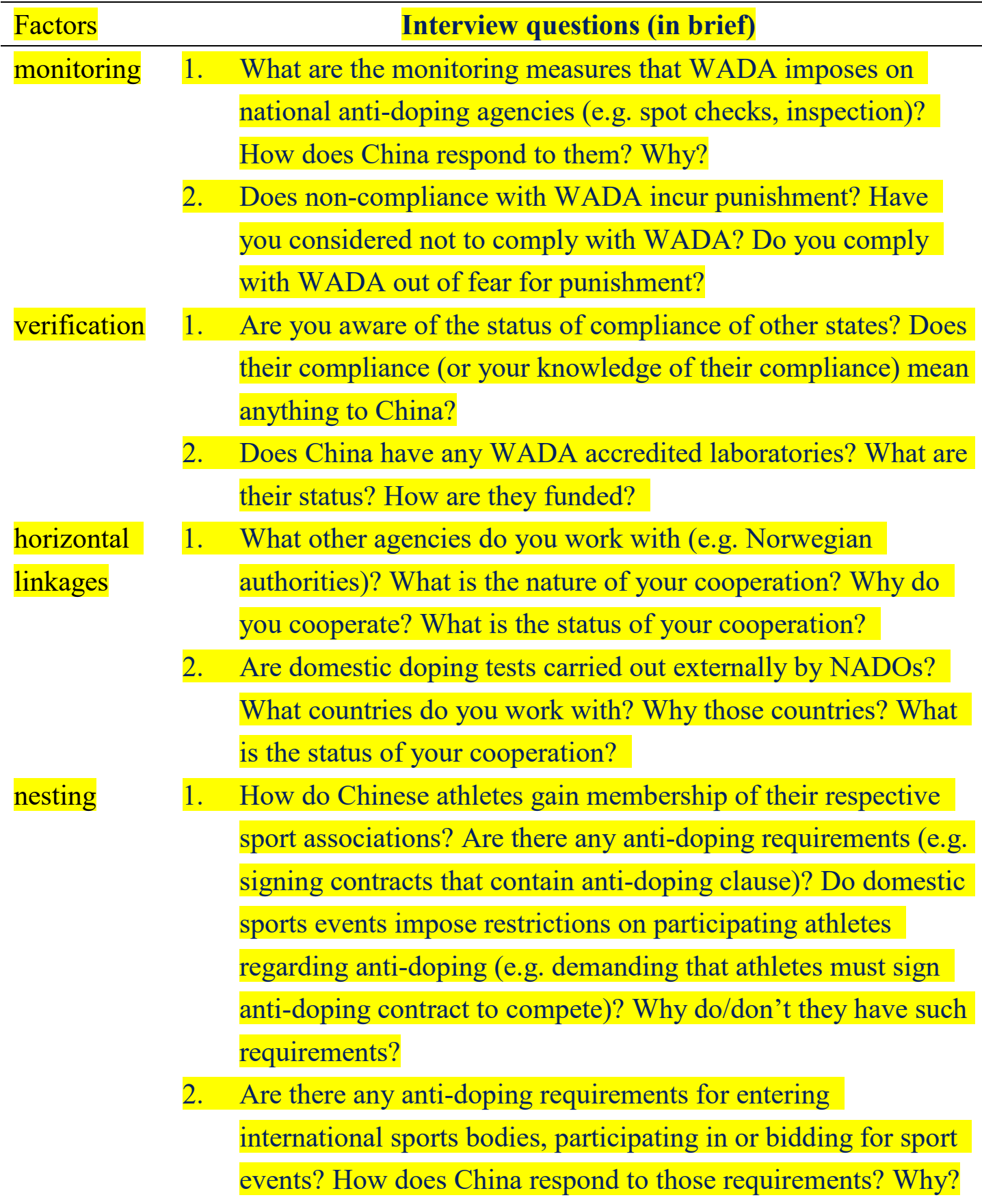


capacity 1. Do international sports bodies provide subsidies for anti-doping building education? Are there other ways of obtaining resource for antidoping education or promotion? What actions has China taken? Why?

2. What is the impact on funding if China fails to comply with the WADA Code? What actions have you taken to avoid this?

national 1. When investigating doping incidents, do you collaborate with concern national police agencies? How? What measures or actions have you taken? Why? What is the status of this collaboration (e.g. cooperative or confrontational)?

2. On the issue of anti-doping, what educational measures have you taken domestically? How do you promote the concept of anti-doping? Why?

institutional 1. On anti-doping, how does China interact with UNESCO? What profile is the status of those interactions? What is the significance of UNESCO to China in terms of anti-doping?

Our second aim was to understand the implications behind those strategies. On this matter, Haas and Bilder (2003) argued that the level of the compliance of state actors with international norms is decided by two factors: 'willingness' and 'capacity', i.e. how states' 'willingness' to comply is influenced by the interest orientation and interaction of domestic stakeholders, and how their 'capacity' to comply is affected by the availability of resources. By combining 'willingness' and 'capacity' as factors affecting state compliance, Haas and Bilder concluded with several scenarios: costly compliance, low-cost compliance and non-compliance. They also analyzed the reasons behind each scenario. For example, if a state is willing and capable of bearing the cost of compliance, it may engage in either low-cost or costly compliance. On the contrary, if a state is incapable of carrying the cost, non-compliance or inability to comply may occur.

Following the above considerations, we adopted documentary analysis - a research tool in qualitative content analysis as our research method as we developed our analytical framework for a study of compliance. The researchers conducted semistructured interviews with Chinese officials handling anti-doping policies, including representatives of the General Administration of Sports of China (GAS), the China Anti-Doping Agency (CHINADA), the Chinese Swimming, Weightlifting, Football and Table Tennis Associations, administrators of Chinese Super League Football and scholars in related fields to seek answers to the two research questions. As regards 
1 China's strategies for managing compliance with the Code, the interviews helped us to

2 examine how China responded to the seven institutional factors with which the

3 international regime seeks to bring states into compliance. On the implications behind

4 those strategies, the interviews focused on the dimensions of 'capacity' and 'willingness'

5 to help determine whether state compliance or non-compliance was at play.

6 Arguably because of the political sensitivity of our research topic, access to 7 interviews did not go smoothly. A lot of time was spent on networking. Fortunately,

8 since 2006, the researchers have made multiple visits to China to investigate elite sports,

9 including soccer, basketball, table tennis, gymnastics and swimming, and have

10 established personal connections. For this study, by requesting repeated interviews and

11 snowball sampling, and with the help of various associates, referrals were made to key

12 sports personnel, including officials at GAS, CHINADA, individual sport associations,

13 sport scholars and leading officials of China's professional sports leagues. Through

14 painstaking efforts, the researchers visited Beijing to conduct field research four times

15 and interviewed a total of 22 policy makers, administrators or scholars who were

16 directly or indirectly involved in China's anti-doping policy (see table 2).

17

18 Table 2 Profiles of interviewees

\begin{tabular}{|c|c|c|}
\hline Interviewee & Affiliated organization/position & $\begin{array}{l}\text { Date of } \\
\text { interview }\end{array}$ \\
\hline $\mathrm{A}$ & $\begin{array}{l}\text { The vice director of the Sports Ethics and } \\
\text { Integrity Risk Research Center, Beijing Sports } \\
\text { University }\end{array}$ & 2015.01 .18 \\
\hline B & $\begin{array}{l}\text { An official from the Athletic Sport } \\
\text { Department, GAS }\end{array}$ & $\begin{array}{l}2015.01 .21 \\
2018.01 .16\end{array}$ \\
\hline $\mathrm{C}$ & $\begin{array}{l}\text { A leading official from the Chinese Table } \\
\text { Tennis Association }\end{array}$ & 2015.01 .21 \\
\hline $\mathrm{D}$ & $\begin{array}{l}\text { A leading official from the Anti- Doping } \\
\text { Division, Chinese Football Association (1) }\end{array}$ & 2015.08 .07 \\
\hline $\mathrm{E}$ & $\begin{array}{l}\text { A leading official from the Anti- Doping } \\
\text { Division, Chinese Football Association (2) }\end{array}$ & $\begin{array}{l}2015.08 .08 \\
2018.01 .19\end{array}$ \\
\hline $\mathrm{F}$ & $\begin{array}{l}\text { A professor from the Research Center of the } \\
\text { Olympic Movement, Beijing Sport University }\end{array}$ & $\begin{array}{l}2015.08 .09 \\
2018.01 .22\end{array}$ \\
\hline G & $\begin{array}{l}\text { An official of the Department of Science and } \\
\text { Education [DSE], GAS }\end{array}$ & $\begin{array}{l}2015.01 .23 \\
2015.08 .06 \\
2017.01 .16 \\
2018.01 .26\end{array}$ \\
\hline $\mathrm{H}$ & A leading official from CHINADA & 2015.01 .13 \\
\hline
\end{tabular}


$\mathrm{K} \quad$ An official in the Division of Legal Affairs and University

\section{Association (1)}

$\mathrm{R} \quad$ A vice chairman of a Beijing professional football club

S A leading official from CHINADA

2015.08.13

$\mathrm{T}$

A former senior official in the Department of

2015.08 .13

Science and Education [DSE], GAS

2018.01.26

\section{Association (2)}

V A former leader of the Chinese Football

Association Super League Co., Ltd

1 Additionally, when handling the interview data, the researchers were aware of the

2 political sensitivity of the topic. Therefore, all interview data have been validated

3 through triangulation before being cited in this paper. The data were compared against

4 other interview data and original sources, including the organizations' internal data,

5 public documents and remarks of leading officials, to establish reliability. Both

6 documentary and interview data were subjected to thematic analysis (Patton, 2002).

7 Back translation was conducted to ensure linguistic consistency after the Chinese

8 material was translated into English.

\section{Research Results and Discussion}




\section{China's Strategies for Managing Compliance with the Code}

Starting in 1978, Chinese leader Deng Xiaoping pushed for the 'Four Modernizations' with the goal of strengthening the fields of agriculture, industry, national defense, and science and technology. China introduced capitalist measures and hoped to swiftly boost its productivity (Oke, 1986). In the early 1980s, sports coaches and performance-enhancing drugs were brought into China from the Soviet Union and the German Democratic Republic in the interests of recruiting high-tech personnel and products (Interviewee K). Some officials of the State Sports Commission (now GAS), influenced by the apparently successful Soviet and East European sports culture, were of the opinion that 'as long as it brings better sports results, poses no harm to athletes and goes undetected by international regulators, the use of performance-enhancing drugs is acceptable'. That comment was later interpreted as 'the three principles of doping: useful, harmless and undetectable' (Yuan, 2009, p. 23). In fact, China's elite sports in the 1990s were heavily plagued by doping scandals. At the 1994 Asian Games in Hiroshima, 11 Chinese athletes tested positive for prohibited substances and were later stripped of all medals and banned for two years. At the 1998 FINA World Championships in Perth, Australia, Chinese swimmer Yuan Yuan was caught carrying human growth hormone and eventually disqualified. Another four Chinese swimmers failed drug tests later in the event (Sun, 2008; Yuan, 2009). As Chinese sports teams were implicated in one doping violation after another at international competitions, many in the West began to question China's growing sports achievements. Some even categorically accused the Chinese government of supplying performance-enhancing drugs to its athletes. In 2002, the world witnessed an example of collective doping unfold at Shenyang Sport School, where school physicians administered the injection of prohibited substances on student athletes. It was the first doping scandal involving students on a campus (Fan \& Lu, 2012). However, as doping in China gradually spread to a younger population, including even adolescents, the severity of the problem became clear. Another major impact was that non-complying signatories of WADA were barred from competing internationally and from hosting mega-sporting events (Interviewees G and J; see also the 2015 WADA Code 20.1.8, 20.3.11, 20.6.6 and 22.8). Facing an apparently never-ending wave of doping revelations, the Chinese government felt obliged to participate in the Second World Conference on Doping in Sport held by WADA in 2003 and committed itself to implementing the Code following the conference (Fan \& Lu, 2012; Yang \& Leaung, 2008). The following discussions dissect China's strategies for managing compliance with the Code in line with the seven factors described in compliance theories, namely, monitoring, verification, horizontal linkages, nesting, capacity building, national concern and institutional profile. An analysis of 
China's strategies in relation to each of these factors will be presented separately.

\section{(1) Enactment and Amendments of Anti-Doping Regulations and Measures for the Administration of Anti-Doping in Response to the Code}

A succession of doping scandals at international competitions from the mid-1990s involving China escalated into diplomatic incidents. The Chinese leadership was under growing pressure to take doping seriously. It added Article 34 to the Sports Law, stating that 'the use of prohibited substances and methods are strictly forbidden, and that drug testing institutions should strictly test against prohibited substances and methods' (General Administration of Sport [GAS], 2000, p. 5). In 1998, GAS issued the Rules Prohibiting the Use of Banned Substances in Sports (Provisional) (Interviewee T). Although the document was swiftly publicised and the then Chinese leader Jiang Zemin publicly declared 'China would rather not take gold medals than resort to doping', the flow of doping scandals did not stop (Yuan, 2009, p. 20). To demonstrate its resolve to tackle doping, China committed itself to anti-doping campaign internationally, joining the newly-established WADA in 1999. As a response to WADA's adoption of the Code in 2004, Chinese Premier Wen Jiabao promulgated the Anti-Doping Regulations which not only provided a legal basis for China's anti-doping policies, but also fulfilled the promise China had made to the IOC when winning the right to host the 2008 Olympics, i.e. prevent doping violations through legislation and other measures (Department of Education, Science, Technology, Culture and Health Legislations, State Council Legislative Affairs Office, GAS, 2004, p.20). Speaking to a seminar on the implementation of the Anti-Doping Regulations, GAS Director Yuan Weimin stressed that with the enactment of the Anti-doping Regulations, 'the Chinese government has demonstrated to the world its solemn attitude and firm position on anti-doping, its support for the international anti-doping campaign and that the Chinese government and China's sports circle have established a good image internationally' (Yuan, 2004, p. 183). Officials from the GAS Department of Science and Education (DSE) emphasized that to be in line with the 2015 edition of the Code, the GAS established and implemented the Measures for the Administration of Anti-doping and the General Rules of Doping Control in 2015 to maintain a high level of compliance with the Code (Interviewee G). To ensure smooth implementation of the Code in China, DSE stressed in its internal documents that it would transform the 2015 edition of the Code into domestic law in the form of a regulatory document (i.e. the General Rules of Doping Control) and issue advisory guidelines on actual implementation to ensure, on a policy basis, that the new rules would be fully implemented (DSE, GAS, 2015). In addition, GAS also ensured that the Chinese Olympic Committee (COC) and CHINADA 
establish Anti-Doping Rules that corresponded to the Anti-Doping Regulations and submit these to WADA to fulfill China's obligations in complying with the Code (Interviewees A, B, G). China's approach was different from that of Norway, a country widely viewed as an anti-doping role model (Hanstad \& Houlihan, 2015; Wagner \& Hanstad, 2011). Although the Norwegian anti-doping agency is publicly funded and its leading officials directly appointed by the Norwegian Olympic and Paralympic Committee, its operation is seen as having a high degree of autonomy. More notably, unlike Chinese legislation, Norwegian laws have not criminalized the use of performance-enhancing drugs.

\section{(2) Establishment of WADA-accredited Laboratories and Anti-Doping Centers}

In 1987, when Beijing secured the hosting rights for the 1990 Asian Games, the Chinese government prepared to set up an anti-doping laboratory. That task was handed to the National Research Institute of Sports Medicine, which had been founded in June of that year, under the State Sports Commission (SSC) (CHINADA, 2016). In 1992, the COC established the Anti-Doping Commission, naming the then Deputy Director of the SSC, Yuan Weimin, as its Chief. The DSE handled day-to-day affairs. Consequently, the drug testing laboratory, established under the aegis of the National Research Institute of Sports Medicine, was directly subordinate to the DSE (Zou, 2013, p. 29). In 1994, Lou Dapeng, Deputy Chief of the Department of Sports Training and Competition of SSC, was renamed Deputy Chief of the Anti-Doping Commission. Using his personal connections, Lou became acquainted with the Chief of the Department of Sport Policy, Ministry of Culture, Norway, who also served on the International Association of Athletics Federations (IAAF). Thanks to the Norwegian official, Norway's anti-doping laboratory assisted China in the establishment of an antidoping laboratory in Beijing in accordance with ISO9001, which later passed WADA's accreditation (Interviewees F, J and T). The lab was created in preparation for the 2008 Olympics and in response to pressure from WADA. However, in 2006, the German media accused the Chinese government of secretly performing gene doping on its athletes, who were expected to win gold medals at the 2008 Beijing Olympics. The report ridiculed the Beijing Olympics as being hosted by a doping country - an observation shared by the then WADA President Dick Pound, who in turn sought explanations from the Chinese authorities. Mounting pressure from the international media and the WADA President was treated with utmost urgency by the Chinese leadership, who instructed the relevant authorities to clarify the situation. According to one DSE official, 'to clear up the misunderstanding, we immediately invited the WADA President to inspect our anti-doping efforts and urged the State Council to form a 
national anti-doping center' (Interviewee G). The official pointed out that immediately after visiting China's anti-doping facilities, the WADA President voluntarily stamped out doping rumors about China at an international press conference, publicly praising China 'as a role model in anti-doping'. Following this incident, the State Council agreed to establish an anti-doping center (CHINADA) under GAS and reorganize the national anti-doping laboratory under its auspices (CHINADA, 2016). However, CHINADA did not operate independently from the Chinese government. In fact, CHINADA was still under the control of GAS, being particularly dependent on DSE policies. In April 2014, the DSE even created an anti-doping division to help implement the 2015 edition of the Code and handle anti-doping affairs, which had become increasingly specialized (GAS, 2015). Although CHINADA wanted to and should be independent, the reality is that under China's current development patterns, most agencies are still directly controlled by the government. Anti-doping laboratories, in particular, need funding support and can hardly operate independently from the government. Even some WADA officials admit that it is understandable for CHINADA to receive large sums of funding from the government (Interviewee L). Our data also show that the Chinese government paid considerable attention to the running of CHINADA because it could affect the national image and China's credentials to host mega-sporting events. Therefore, the government invests heavily in CHINADA in the hope of gaining recognition from the IOC and WADA (Interviewees G, H, S and T). It is also worth noting that China's anti-doping tasks are led by the newly-established anti-doping division of the DSE, GAS, and not by any elements of the elite sport sector. This helps to maintain a separation of powers among the departments to avoid conflicts of interest. The addition of an anti-doping division under GAS, considered rare at a time when China was downsizing its sports administrative system (Interviewees G, J and M), reflected how much emphasis the Chinese government put on anti-doping. In addition, during the interviews, two leading officials from CHINADA revealed their desire to unshackle themselves from GAS, operating as a non-profit organization completely independent from government (Interviewees H, S). However, in April 2016, four months prior to the Rio Olympics, an anti-doping lab under CHINADA was hit with a four-month suspension as it had failed WADA's blind tests (accreditation already reinstated by the end of August, 2016) (WADA, 2016). Later, when 31 Chinese athletes from the Beijing Olympics tested positive for prohibited substances upon retesting, the management problem of CHINADA was completely exposed (Interviewee G). The latest scandal disgraced the Chinese leadership, prompting the government to reshuffle the leadership of CHINADA. In addition to renaming Chen Zhiyu, Deputy Chief of DSE handling antidoping affairs, as the new Deputy Director of CHINADA (GAS, 2017), the government also designated Li Yingchuan, Assistant to GAS Director at the time, as Director of 
1 CHINADA concurrently. The purpose was to strengthen China's anti-doping

2 administration to facilitate anti-doping operations for the 2022 Winter Olympics in

3 Beijing. In addition, a senior official from the DSE, GAS also emphasized that 'we are

4 preparing to set up a second anti-doping laboratory aiming to pass WADA's

5 accreditation for the 2022 Winter Olympics and to demonstrate our commitment with

6 the Code (Interviewee T).

7

\section{(3) Seeking International Cooperation in Anti-Doping}

Following the scandals at the 1994 Asian Games, during which several Chinese athletes in swimming, track and field and cycling were caught doping (Department of Education, Science, Technology, Culture and Health Legislations, 2004), the Chinese government actively sought cooperation with overseas anti-doping agencies. It signed bilateral agreements with countries such as Australia, Canada, Norway and Sweden to promote collaboration and exchange, and also launched exchange activities with France, the UK, etc. Through mutual visits of personnel, information exchange, operations evaluation and collaborative research with other countries, China hoped to bolster its anti-doping efforts (Interviewee S). Among the many overseas partners, Australia and Norway have been the closest to China. Australia was an advanced country in the world's anti-doping community and had won the right to host the 2000 Olympics. It was among the first countries to contact China, hoping to initiate bilateral exchange on anti-doping. Initially, China hesitated, but soon felt isolated and helpless in light of the 1994 doping scandals and desperately needed help from the outside. In these circumstances, China signed a formal agreement with Australia to begin annual exchanges. Although the bilateral exchange program ended after the Sydney Olympics due to Australia's lack of funding, it paved the way for the current reciprocal testing between the two countries (Interviewee H). In an interview, a former DSE official pointed out: While the exchange agreement was partly motivated by Australia's desire to monitor Chinese athletes against doping and ensure fair play at the Sydney Games, it nevertheless boosted China's anti-doping development to a certain extent (Interviewee T).

As for China's collaboration with Norway, the two countries have maintained close ties between their anti-doping laboratories since the 1990s. After the 2008 Olympics, China ran neck-and-neck with Norway in terms of drug-testing capabilities. WADA President Dick Pound even publicly praised China for playing a leading role in anti-doping following the Olympics. CHINADA officials believed that WADA deemed China and Norway to be top performers in anti-doping and therefore called on the two 
countries to collaborate in helping Kenya to establish its anti-doping agency. 'It was a way of recognizing China's anti-doping achievements by WADA, but also an export and manifestation of China's soft power' (Interviewees K, L), one CHINADA official said, 'To be frank, the three WADA assistance programs currently underway around the world, namely, Canada assisting Jamaica, the US and the UK helping Brazil, China and Norway supporting Kenya, are all examples of "good students leading bad students"” (Interviewee K).

\section{(4) Promoting the Special and Important Role of Anti-Doping Issues among Domestic Sports Bodies}

According to a former senior DSE official, change in China's anti-doping policy was often associated with international events and major doping scandals. A particular case in point was the scandal at the 1998 FINA World Championships in Perth, Australia (Interviewee T), after which the Chinese leader Jiang Zemin declared unequivocally to China's sports circle, '[China] would rather not take gold medals than resort to doping' (Yuan, 2004, p. 183). Jiang made this statement to ease growing international pressure. But for Yuan Weimin, the newly appointed GAS Director, the pressure of having responsibility for China's success at the upcoming Sydney Games was enormous. In his memoir, Yuan stated, 'I was under huge pressure! Among the athletes who failed GAS random drug tests and thereby lost the chance to compete in Sydney, several could have won gold medals. If someone was caught doping, I took the blame. If athletes didn't perform well, I took the blame. If Beijing's Olympic bid was compromised due to doping, I would be given an extra "charge"' (Yuan, 2004, p. 30). In fact, as Yuan said, 'the problem of doping concerns national pride and the image of Chinese athletes. It is a "political" issue. It affected Beijing's bid for the Olympics. GAS must raise the banner of anti-doping and must not waver' (Yuan, 2004, p.22). As doping escalated into a 'political' issue, anti-doping began to play a special and important role in China's sports administration. It became obligatory for every sport governing body under the GAS to designate one deputy chief to anti-doping duties (Interviewees M, R and V). In addition, to ensure the cleanness of the Chinese national athletes competing abroad, the authorities strengthened the control and screening of athletes' food intakes, dietary supplements and medication. More importantly, athletes now had to pass CHINADA's drug screening before competing overseas (Interviewee I).

\section{(5) Securing Funding for Domestic Anti-Doping Operations}


China's anti-doping policies are mainly formulated by the Anti-Doping Division of DSE and GAS and are primarily implemented by CHINADA. Under the direct supervision of GAS, CHINADA is a public-sector organization fully funded by the government. Administratively, it runs like any other government agency and is headed by a Director directly appointed by GAS (Zou, 2013, p. 38). According to one of its leading officials, CHINADA's operating expenses, including utilities, equipment, refurbishment and personnel costs, are fully funded by the government. Every year, the government allocates special funds to CHINADA for drug screening and anti-doping education (Interviewee H). The official added, 'when we began in 1990, we tested a little more than 160 samples. The numbers have gone up to about 8000 samples every year. These tests were all funded by the government'. To ensure national athletes were doping-free, all first-string and second-string members of Chinese national teams, which amounted to more than 4000 athletes, were gathered and tested. According to some officials from individual sport associations, the national weightlifting team was tested most frequently, at an interval of once per week. Coming next were the swimming and track and field teams which were tested once or twice per month (Interviewees I, P, Q, U). This supports the GAS official's suggestion that China has stepped up antidoping and now conducts multiple tests each month (Interviewee G). Meanwhile, screenings seemed to be cascading down from the elite sports system, to cover sports schools at the provincial level. A GAS official revealed, 'by doing so, we can ensure that student athletes do not dope, and that our national teams are safe' (Interviewee H). Testing expenses for preparation for the Olympics are met with additional funding. The official stressed, 'to ensure that no Chinese athletes competing overseas generate any negative news, we spent an additional 10 million yuan just for the 2012 London Olympics alone'. Understandably, drug test funding for the 2016 Rio Olympics was inevitably higher. Due to the enormous costs of drug tests, in addition to the 8000 samples funded by the central government each year, GAS is developing a system of bottom-up supervision. It holds provincial and municipal governments responsible for the costs of testing their athletes in order to expand the scope of screening (Interviewees $\mathrm{G}, \mathrm{H})$. According to the DSE official, 'Anti-doping is gaining a lot of momentum in China with the leadership's backing. In particular, this coincides with China's bid for the 2022 Winter Olympics, so we are expecting a great leap forward' (Interviewee G). To cope with the expansion of test subjects (including sports school test takers, elite athletes and professional athletes) and growing drug test expenses, GAS reached an agreement with Shanghai city government to establish China's second anti-doping laboratory funded by the city government. As well as carrying out more drug tests on professional athletes, the new laboratory would also perform drug tests during 
Ministry of Education (Interviewee G). Eventually China's second anti-doping laboratory was established in Shanghai city on 3rd April, 2018 (Zhu \& Gao, 2018).

\section{(6) Making Anti-Doping Commitment an Entry Criterion for National Sports} Teams as a Measure to Promote Anti-Doping Education

When Yuan Weimin took the helm of GAS in the late 1990s, GAS began demanding that athletes, coaches, sport administrative centers and sports event organizers sign an anti-doping commitment statement, which later evolved into a twofold system: an anti-doping commitment statement signed by sports administrative bodies and the athletes' commitment to anti-doping as an entry criterion for national teams. In the Notice on Chinese Delegation's Anti-doping Work at Multi-sport Events in 2014 (hereinafter referred to as 'the Notice'), it is stressed that 'GAS will sign a Responsibility Statement of the Chinese Delegation's Commitment to Anti-doping, Sports Culture and Sports Ethics with pertinent sports authorities and enact the "Rules regarding Anti-doping and Medical Work for the Chinese Delegation", clearly designating the leading official of each sports body as the person in charge of its antidoping responsibilities and that the team leaders are directly responsible for their team's anti-doping work' (DSE, GAS, 2013). Simply put, when dividing administrative responsibilities for anti-doping, GAS is holding the leading officials of sports bodies directly responsible. According to the GAS officials, if a doping incident occurs, those leading officials who have signed a commitment statement would not only be severely punished but would also be likely to be excluded from any promotion in the future. This is because the national leadership takes anti-doping very seriously (Interviewees G, N, $\mathrm{O})$.

On making an anti-doping commitment a criterion for entering national teams, the Notice dictates '[we] need to uphold the principle of "prevention first, education as fundamental". Prior to every sports event, all pertinent authorities must mobilize their athletes and support personnel to study anti-doping knowledge, take joint exams and sign anti-doping statements. Athletes and support personnel must attend classes and pass exams as demanded to qualify for the Chinese delegation'. The Notice also emphasizes, "pertinent authorities should designate personnel to be in charge of these affairs, fully implementing anti-doping education, examination, signing of anti-doping statements and promotion. They should utilize this system as an effective measure to strengthen anti-doping education and must not treat it perfunctorily or simply as a matter of formality' (DSE, GAS, 2013). Interviews with China's swimming, weightlifting, track and field, table tennis and football associations revealed that the anti-doping entry criterion has now been fully adopted in the selection of national 
athletes in these sports (Interviewees C, D, E, P, Q and U). An official from the Chinese Weightlifting Association pointed out, 'all weightlifters and their coaches must attend anti-doping classes, pass exams and re-sign a commitment statement before they can compete abroad' (Interviewee I). The official admitted that the entry criterion has greater declaratory significance than actual effects. Nevertheless, he stressed, 'after signing the commitment statement, those who violate the rules shall take punishment voluntarily'. In other words, the system deters and prevents athletes and coaches from violating anti-doping rules.

Additionally, to ensure the fairness of the admission exams for college-level sports programs, China has begun running drug test sites for examinees; these are fully funded by the Ministry of Education, supervised by the DSE and implemented by CHINADA and the school authorities (DSE, GAS, 2014). According to the DSE official, the test sites were set up due to growing concerns on the part of central government and education officials following several incidents in which examinees died during skill tests due to doping (Interviewees G, T).

\section{(7) Maintaining Good Relations with WADA, IOC and UNESCO}

In 1997, China began participating in the Monitoring Group of the Anti-Doping Convention as an observer. Since WADA's formation in 1999, as a major Asian country, China has been represented on WADA's foundation board by a GAS Deputy Director who manages China's elite sports (GAS, 2015, p. 18). Furthermore, the Chinese government sets aside 240,000 US dollars annually for funding WADA's operations (Interviewees H, S). It should be noted again that WADA's founding President Dick Pound spoke highly of China's anti-doping organizations after his inspection tours in China in 2007. Ironically, however, following the Beijing Olympics, the then WADA President John Fahey and Director General David Howman said publicly in 2013 that China produced $99 \%$ of the world's illegal substances (Sun, 2013). This claim disgruntled the Chinese leadership, even prompting the then GAS Deputy Director Duan Shijie, who served on the WADA Foundation Board at the time, to lodge a protest in writing (Duan, 2013). Despite the row, the incident eventually led to cooperation between China and WADA, combating the production, selling and trade of illegal substances (WADA, 2015a). Howman believed this was 'a step forward in collaboration' between China and WADA (Ma, 2015). A GAS official also pointed out that the WADA-China relationship is at its best stage of constructive interaction wherein both sides support and understand the work that needs to be done. As a great power but also a major producer of raw materials for illegal substances, China needs to close the loophole (Interviewee G). 
During the 2014 Nanjing Youth Olympics, Liu Yandong, a Chinese Politburo member and Vice Premier, met with WADA's newly-elected President and IOC Vice President Sir Craig Reedie, assuring him of the Chinese government's full support for Agenda 2020, an anti-doping strategic roadmap proposed by IOC Chairman Thomas Bach. Like Japan, China pledged one million US dollars to the IOC Anti-doping Research Fund to strengthen its collaboration with the IOC (GAS, 2015, p.34). Furthermore, in 2005, China was among the first countries to sign the UNESCOinitiated International Convention against Doping in Sport as a move to recognize the effectiveness of the Code. According to a leading official of CHINADA, China regularly sends representatives to attend UNESCO-held Convention meetings and serve vice chairmen at the Convention's executive committee. It also donates annually to UNESCO-affiliated foundations, which provides funding to countries to start their anti-doping programs (Interviewee $\mathrm{H}$ ).

\section{The Main Drivers and the Significance of China's Compliance Strategies}

From the above analysis of the seven dimensions of China's compliance strategies, which was based on the seven dimensions identified in compliance theories, one can infer that China's signing of the Code and its compliance were driven by both external and internal factors. Externally, it was mainly motivated by the international realities of the time and especially by the fact that Chinese athletes were to compete with athletes from other countries (Interviewees A, G, T). From the 1980s to early 1990s, China's officials were heavily influenced by Soviet and East European sports culture and did not believe doping was wrong. On the contrary, China saw doping as an application of high-tech products, leading to the three principles of doping: usefulness, harmlessness and undetectability. That thinking was increasingly challenged when the IOC and the European Union began to address the threat of doping and the issue of fairness in sports competitions. A wind of change blew through the international community as more and more countries came to believe that sending doping athletes to compete was deceitful, unethical and seriously violated the IOC's firmly held principle of fair play. As the IOC toughened anti-doping drug tests and worldwide public opinion began to notice and condemn doping countries and athletes, China found itself in the storm center of a series of doping scandals in the late 1990s when Chinese athletes competing abroad were caught doping collectively. Those incidents were viewed as international scandals involving state-directed systematic doping in order to give athletes an unfair advantage over others. The severity of the scandals led to diplomatic incidents, tainting China's 
image and reputation in the world. International pressure forced the then Chinese leader Jiang Zemin to publicly declare that China's sports community 'would rather not take gold medals than resort to doping' (Yuan, 2009, p. 20). The cost of taking the antidoping path for China was enormous, not least because it could undermine the country's performance in international competition. However, China was capable of choosing to comply with the IOC's anti-doping policy at the time and with the Code that followed. It should be noted that China's strength and performance in elite sports did not decline significantly as a consequence of its anti-doping efforts. In fact, at the 2008 Beijing Olympics, China overtook the United States to top the medal table and became the new superpower in sports. Even at the 2012 London Olympics, Chinese athletes finished with their best performance at an Olympics held outside of China.

The internal drivers for China's compliance can be linked to China's status as a bidder and/or host of international sports events and as a rising power. Bidding for and hosting sports mega-events, especially the Summer and Winter Olympics, had been China's century-old dream. By hosting the Olympics, China hoped to remove the stigma of 'the sick man of East Asia' that had haunted people since the Opium Wars in the mid-19th century. For this reason, anything that could potentially derail China's Olympics bidding or hosting prospects had to be eradicated. It is unsurprising that former GAS Director Yuan Weimin called doping a 'political' problem, since doping could have jeopardized Beijing's 2008 Olympic bid and China was obliged to carry the anti-doping banner. In its response to the IOC and the Code, China was clearly aware of the great cost involved in compliance. In particular, the response called for regulatory changes, the establishment of anti-doping institutions, and large subsidies and input of manpower from the central government. Despite the high cost, however, China has gradually displayed its strength as a great power with the successful hosting of the 2008 Beijing Olympics and winning the bid for the 2022 Winter Olympics. Furthermore, after becoming leader of China, President Xi Jinping unveiled the China Dream, which called on the country to ascend from being a sporting power to a sporting superpower (Tan, \& Houlihan, 2013; Tan, Huang, Bairner \& Chen, 2016). While treating sport as a platform upon which to demonstrate and export its culture and use soft power, China spared no effort to demand a clean image from its athletes, safeguard its national reputation and pursue the China Dream of becoming a sporting superpower. In complying with the Code, China has shown zero tolerance for mistakes despite the enormous cost.

\section{Conclusion}

In terms of compliance strategies, China has responded to the international anti- 
1 doping regime in each of these seven dimensions separately: monitoring, verification,

2 horizontal linkages, nesting, capacity building, national concern and institutional

3 profile. In monitoring, China has enacted and amended the Anti-doping Regulations

4 and the Measures for the Administration of Anti-doping in accordance with the 2015 edition of the Code. In terms of Verification, China is set to establish its second WADA6 accredited laboratory in Shanghai after Beijing's. As regards creating horizontal 7 linkages, China has collaborated closely with Norway and has assisted Kenya by 8 providing technical training and guidance for its anti-doping institution. With reference to nesting, China has demanded that Chinese athletes, coaches, sports administrative

10 centers and sports event organizers sign an 'anti-doping commitment statement'. In the interests of capacity building, the Chinese government has not only provided full funding support to domestic anti-doping campaigns but has also donated one million US dollars to the IOC Anti-Doping Research Fund, which has worked closely with WADA. By raising national concern, the Chinese government has developed antidoping teaching materials, provided anti-doping education and set up drug test sites for sports school test takers. Finally, by strengthening its institutional profile, China has actively participated in UNESCO events and was one of the initiators of the International Convention against Doping in Sport.

China's signing of and compliance with the Code were driven by a combination of external and internal factors. Externally, these actions were linked to China's doping scandals in the 1990s, media exposure and diplomatic pressure that came with the scandals, and the fear that Chinese athletes could be barred from competing at the Olympics. Internally, China was influenced by its desire to bid for Winter and Summer Olympics. The implication of China's compliance is that the Chinese government has attained a level of compliance in terms of willingness and capability. Houlihan (2014) and Hanstad \& Houlihan (2015), who have long paid attention to anti-doping policy, point out that the level of 'commitment' to compliance cannot be easily measured. However, our evidence suggests that China is willing to pay a high price to comply with the Code. This study, thus, concludes that if the Chinese leadership continues to believe that participation in, bidding for and hosting mega-sporting events (especially the Olympics) are important to the country's development, China will continue to pay a high price to comply with the Code. In terms of theoretical applicability, this study shows that, in the WADA Code, the provisions relating to compliance can be categorized as comprising seven factors, and that the response strategies of national agencies can also be broken into seven factors. More importantly, our theoretical framework helps us understand how international organizations bring national agencies into compliance, and how states respond to the seven factors of compliance. This confirms Robert K. Yin's claim that 'articulating "theory" about what is being studied 
helps to operationalize case study designs and make them more explicit' (Yin, 2003:

19).

\section{References}

Antonopoulos, G. A., \& Hall, A. (2016). Gain with no pain": Anabolic-androgenic steroids trafficking in the UK. European Journal of Criminology, 13(6), 696-713.

China Anti-Doping Agency (2016). CHINADA introduction. Retrieved from http://www.chinada.cn/zsxjs/index.jhtml.

de Hon, O. (2017). The redundancy of the concept of 'spirit of sport' in discussions on the prohibited list of doping substances. International Journal of Sport Policy and Politics, 9(4), 667-676.

Department of Education, Science, Technology, Culture and Health Legislations, State Council Legislative Affairs Office, GAS. (2004). Fanxinfenji tiaoli shiyi [Interpretation of anti-doping regulations]. Beijing: Xinhua.

Department of Science and Education, GAS. (2014). Guanyu zuohao 2014 nian guojizonghexing yundonghui zhongguo daibiaotuan fanxinfenjigongzuo youguan shiyi [Notice on Chinese delegation's anti-doping work at multi-sport events in 2014]. Retrieved from http://www.sport.gov.cn/n16/n33193/n33208/n33508/n34222/5346595.html

Department of Science and Education, GAS. (2015). Zhongguo Fanxinfenji 2014 [China's anti-doping efforts in 2014]. Beijing: GAS.

Duan, S. (2013). Zhi Shijiefanjinyaozuzhi Zongganshi Dawei Haoman De Yifengxin [A letter to WADA director-general David Howman]. Tiyu Daode Yu Lianzheng [Sports Ethics and Clean Governance], 2, 6.

Efverström, A., Bäckström, Å. Ahmadi, N., \& Hoff, D. (2016). Contexts and conditions for a level playing field: Elite athletes' perspectives on anti-doping in practice. Performance Enhancement and Health, 5(2), 77-85.

Elbe, A. M., \& Overbye, M. (2014). Urine doping controls: the athletes' perspective. International Journal of Sport Policy and Politics, 6(2), 227-240.

Fan, H., \& Lu, Z. (2012). The politics of doping and anti-doping in Chinese sport. The International Journal of the History of Sport, 29(1), 132-144.

Haas, P. M., \& Bilder, R. B. (2003). Compliance theories. In D. Shelton (Ed.), Commitment and compliance: The role of non-binding norms in the international legal system (pp. 43-74). New York: Oxford University Press.

Hanstad, D. V., \& Houlihan, B. (2015). Strengthening global anti-doping policy through bilateral collaboration: the example of Norway and China. International Journal of Sport Policy and Politics, 7(4), 587-604.

Henne, K. (2015). Defending doping performances and trials of an anti-doping program. Journal of Sport and Social Issues https://doi.org/10.1177/0193723515596203

Henning, A. D., \& Dimeo, P. (2015). Questions of fairness and anti-doping in US cycling: The contrasting experiences of professionals and amateurs. Drugs: Education, Prevention and Policy, 22(5), 400-409.

Houlihan, B. (2002a). Managing compliance in international anti-doping policy: The World Anti-Doping Code. European Sport Management Quarterly, 2(3), 188- 
208.

Houlihan, B. (2002b). Dying to win: Doping in sport and the development of antidoping policy. Strasbourg: Council of Europe.

Houlihan, B. (2008). Detection and education in anti-doping policy: A review of current issue and an assessment of future prospects. Hitotsubashi Journal of Arts and Sciences, 49, 55-71.

Houlihan, B. (2014). Achieving compliance in international anti-doping policy:An analysis of the 2009 World Anti-Doping Code. Sport Management Review, 17, 265-276.

Houlihan, B. (2015). The Future of Anti-Doping Policy. In V. Møller, \& I. Waddington, \& J. Hoberman (Eds.), Routledge Handbook of Drugs and Sport (249-259). London: Routledge.

Hunt, T. M. (2015). Anti-Doping Policy Before 1999. In V. Møller, \& I. Waddington, \& J. Hoberman (Eds.), Routledge Handbook of Drugs and Sport (209-218). London: Routledge.

Liu, M. (2003). Shijie Fanundongjinyao Zuzhi Qianshu Gebenhagen Fanjinyao Xuanyan [WADA Signed Copenhagen Declaration on Anti-Doping in Sport]. Retrieved from http://www.epochtimes.com/b5/3/3/6/n283240.htm

Loland, S., \& Hoppeler, H. (2011). Justifying anti-doping: The fair opportunity principle and the biology of performance enhancement. European Journal of Sport Science, 12(4), 347-353.

Lombardi, G., Perego, S., Sansoni, V., \& Banfi, G. (2016). Circulating miRNA as fine regulators of the physiological responses to physical activity: Pre-analytical warnings for a novel class of biomarkers. Clinical Biochemistry, 49(18), 13311339.

Ma, X. (2015). Zhongguo yu WADA jiang lianshou daji feifa xinfenji yuancailiao chanxiao [China and WADA work hand-in-hand to combat the production and selling of illegal substances]. Retrieved from http://news.xinhuanet.com/sports/2015-09/19/c_128246807.htm (accessed 29 April, 2016). Notes

Malcolm, D., \& Waddington, I. (2008). 'No systematic doping in football': A critical review. Soccer and Society 9(2):198-214.

Maughan, R. J. (2007). Contamination of dietary supplements and positive drug tests in sport. Journal of Sports Sciences, 23(9), 883-889.

Mazanov, J., Huybers, T., \& Connor, J. (2012). Prioritising health in anti-doping: What Australians think. Journal of Science and Medicine in Sport, 15(5), 381385.

Miah, A. (2006). From anti-doping to a 'performance policy' sport technology, being human, and doing ethics. European Journal of Sport Science, 5(1), 51-57.

Newsham, K. R., \& Mokha, M. (2017). Performance enhancement and health care professionals' ethical obligation. International Journal of Athletic Therapy and Training, 22(1), 19-23. 
Oke, S. (1986). China's relationships with the world economy: Trade, investment and contemporary developments. Journal of Contemporary Asia, 16(2), 201-223.

Patton M (2002) Qualitative Research and Evaluation Method. Thousand Oaks, CA: SAGE.

Sefiha, O., \& Reichman, N. (2016). When every test is a winner: Clean cycling, surveillance, and the new preemptive governance. Journal of Sport and Social Issues, https://doi.org/10.1177/0193723516632045

State General Administration of Sports (2015). Anti-doping in China. Beijing: GAS.

State General Administration of Sports (2017). Guojiatiyuzongju renshi renmian 2016 niandu [The appointment and the removal of GAS personnel for the year 2016]. Retrieved from http://www.sport.gov.cn/n315/n327/n396/c788662/content.html

Stewart, B., \& Smith, A. (2004). Rethinking drug use in sport. London, UK: Routledge.

Sun, C. Y. (2013). World leading anti-doping agencies claimed ninety-ninepercent of the world's illegal substances were from China. Retrieved from people.cn. Website: http://sports.people.com.cn/n/2013/0220/c22155-20540159.html

Tan, T. C.\& Houlihan, B. (2013). Chinese Olympic Sport Policy: Managing the Impact of Globalisation. International Review for the Sociology of Sport, 48 , $131-152$.

Tan, T. C., Huang, H.C., Bairner, B., \& Chen, Y.W. (2016). Xi Jin-Ping's World Cup Dreams: from a Major Sports Country to a World Sports Power. The International Journal of the History of Sport。 33 (12), 1449-1465

Waddington, I., \& Møller, V. (2014). Cannabis use and the spirit of sport: A response to Mike McNamee. Asian Bioethics Review 6(3), 246-258.

Wagner, U. (2011). Towards the construction of the World Anti-Doping Agency: Analyzing the approaches of FIFA and the IAAF to doping in sport. European Sport Management Quarterly, 11(5), 445-470.

Wagner, U., \& Hanstad, D. V. (2011). Scandinavian perspectives on doping-A comparative policy analysis. International Journal of Sport Policy and Politics, 3(3), 355-372.

Wang, Z., Zhou, X., Liu, X., Dong, Y., \& Zhang, J. (2017). A novel HPLC-MRM strategy to discover unknown and long-term metabolites of stanozolol for expanding analytical possibilities in doping-control. Journal of Chromatography B: Analytical Technologies in the Biomedical and Life Sciences, 1040, 250-259.

Wilson, W., \& Derse, E. (2000). Doping in elite sport. Champaign, IL: Human Kinetics.

World Anti-Doping Agency (2015a). WADA and China sign ground-breaking agreement to eliminate illegal manufacture and supply of PEDs. Retrieved from https://www.wada-ama.org/en/media/news/2015-09/wada-and-china-signground-breaking-agreement-to-eliminate-illegal-manufacture

World Anti-Doping Agency (2015b). World Anti-Doping Code 2015. Montreal: Author.

World Anti-Doping Agency (2016). WADA suspends the accreditation of the Beijing laboratory. Retrieved from https://www.wada-ama.org/en/media/news/201604/wada-suspends-the-accreditation-of-the-beijing-laboratory 
1 Yang, D. L., \& Leung, A. (2008). The politics of sports anti-doping in China: Crisis, 2 governance and international compliance. China: An International Journal, 6(1), 3 121-148.

4 Yin, (2003). Case Study Research: Design and Methods. London: Sage Publications, 5 Inc.

6 Yuan, S. (2009). Yuan Weimin yu titan fengyun [Yuan Weimin and sports]. Jiangsu, 7 China: Jiangsu Renmin.

8 Zhu, X., \& Gao. J. D. (2018). Shanghai chengli xingfenji jiance shiyanshi wei 2022 9 dongao tigong baozhang [Shanghai set up doping control laboratory to provide protection for the 2022 Winter Olympics]. Retrieved from http://sports.sina.com.cn/others/others/2018-04-04/doc-ifysuuya3248311.shtml management system of China (Unpublished doctoral dissertation). Beijing: Beijing Sport University. 